\title{
Evaluating multifunctional land use and livestock farming: a co-evolutionary approach among farmers and consumers
}

\author{
Concettina Guarino ${ }^{\dagger}$ and Francesco Di lacovo
}

University of Pisa, Department of Animal Production Science, Italy

\section{Introduction}

Although the principles of sustainable agriculture are broadly accepted and have been on the political agenda of international and national institutions for quite some time, its systematic consideration in practical farm management is still very limited (Pintér and Häni, 2006). However the treatment of production and consumption in agro-food studies is still highly asymmetric and little value is assigned to the reciprocal relationships consumer-farmer in building of sustainable models (Goodman and Dupuis, 2002). These considerations call for the translation, in common terms, of sustainable agricultural principles on the one hand and for a reconsideration of the role played both by farmers and citizens/consumers on the other.

This research aims to contribute to the achievement of these objectives through a holistic and practical self-assessment tool for use at farm level with the purpose of provoking a co-evolutionary process of consumers and producers practices.

This paper considers a user-friendly tool relevant to community evaluation using practical guidelines.

\section{Methodology}

The methodology set up had the double objective of providing a self-evaluation tool for farmers and promoting sustainable patterns at local levels. It is presented in the figure below.

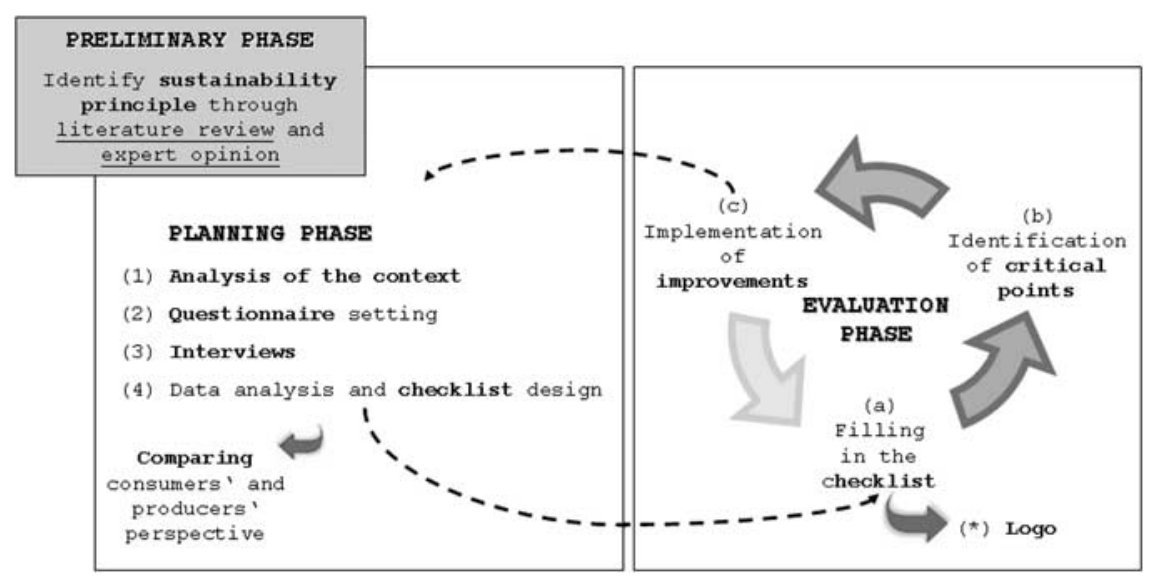

The preliminary stage of this methodology is the identification of the principles of sustainability. A literature review on the subject and in particular the analysis of publications and reports of international organisations was carried out. The information collected was organised following a basic structure where a goal is selected first, then an objective, then a strategy and finally an action step. This scheme has been chosen in order to spell out the general principle of sustainability in concrete and tangible details and understandable to stakeholders. The goals define the three dimensions of sustainability: environmental, economic and social. The action steps are the multiple functions that agriculture can perform. At this level a first element of connection with the territory emerges: the specific functions must be identified specifically for each area; agricultural activity does not perform the same functions in all areas (1). On the basis of the scheme resulting from the previous stage, a questionnaire (2) is set up. The questionnaire is the tool used to carry out an empirical study into perceptions on sustainability of livestock farming. The first question, called the reference question, measures the weight assigned to each specific objective in relation to the general goal; the second question estimates the perceived importance of each strategy in achieving the specific objective; the last question evaluates whether respondents believe the implementation of strategy poses a potential problem in present local livestock farming (evaluative belief). (3) Respondents are selected according to their proven interest and sensibility towards a sustainable production/consumption (purposive sampling procedure). The data stored are analysed with two objectives considered (4): on the one

\footnotetext{
${ }^{\dagger}$ E-mail: cguarino@vet.unipi.it
} 
hand the results from the two samples are evaluate in order to rank the scores and make a comparison, on the other a priority scale among the different aspects of sustainability is set as an input for the next step. Weighting each aspect of sustainability on the basis of the scores assigned by consumers enables a checklist to be set up. The checklist is a self-evaluation tool farmers can use to identify possible practices to adopt in order to improve their own degree of sustainability (learning); to understand how much sustainability is perceived by consumers (accountability); to identify critical points and to try to improve or to check the effects of any change - comparing baseline and follow-up evaluation (decision making); as a communication tool, when both farmers and consumers recognise the logo generated by the system.

\title{
Results
}

The whole tool has been tested in a specific study area and some relevant aspects arise: the high degree of detail and specificity charactering the tool answers a lot of the reliability issues but causes limitations to transferability; whereas the planning phase requires specific knowledge and skills, in the evaluation phase the single farmer can work autonomously.

\section{Conclusions}

Looking at future scenarios, in terms of assessment instruments, there is increasing demand for manifold assessment tools able to conciliate relationships among stakeholders. This first attempt could be improved. In particular, through its application in different contexts, the tool could be further tested, strengthened and comparisons made. Conditions for transferability should be identified.

\section{References}

Goodman D and Dupuis EM 2002. Knowing Food and Growing Food: Beyond the Production-Consumption Debate in the Sociology of Agriculture. Sociologia Ruralis $42,5-22$.

Pintér L and Häni F 2006. From Common Principles to Common Practice. International Forum on Assessing Sustainability in Agriculture (INFASA).

\section{A holistic approach is needed to improve the performance of the livestock sector in supporting food security in the French West Indies: an offer from the research institutes}

\author{
A. Hiol ${ }^{1 \dagger}$, K. Rochefort ${ }^{2}$ and G. Alexandre ${ }^{3}$ \\ ${ }^{1}$ IUT Pole Guadeloupe Industries alimentaires et biologiques, St Claude, 97120; ${ }^{2}$ Pole Agro-Alimentaire Regional de Martinique, Lamentin, $97232 ;{ }^{3}$ INRA URZ 143 \\ Domaine Duclos Petit-Bourg Guadeloupe, 97170
}

\section{Introduction}

Animal production in the FWI is in an unfavorable position with a decline in traditional markets and increased demand for imported goods. Such a situation requires the creation of essential conditions for growth of the domestic animal sector in terms of global competition and technological development. This paper focuses on strategies to improve the value of animal and meat products in the FWI. Many criteria must be taken into account to achieve this purpose: i) emergence of standardization in meat quality which includes security may assist response to competiveness; ii) innovative technologies in meat processing are necessary for economic development and have repercussions on the agro-nutritional system, allowing reductions in cost, increases in efficiency of production and provision of greater employment opportunities; iii) typical territorial products contribute to the potential for development of niche sectors and rural areas. In his context strong relationships between food quality and security and sustainable development is needed. The quality of animal products is the result of a combination (Figure 1) of several factors, including traceability for microbiology and chemical safety (tracing and tracking), nutritional value and organoleptic characteristics, utilization (shelf-life, user-friendly, packaging quality), cultural aspects (tradition, area of origin, genuineness) as well as ethical - social aspects (protection of ecosystem, flora, fauna, animal health). Food security is derived from all these factors which is more or less a combination of practices and requirements that aim to guarantee the high quality of a food product. Some tools to guarantee food security must be implemented within the whole animal sector and through any process. Mandatory food traceability allows the reconstruction and following of the different animal feed processing phases. Labeling is the principal and most direct instrument which permits consumers to be aware of the specific characteristics of a food and of its relation to cultural values.

\footnotetext{
† E-mail: ahiol@univ-ag.fr
} 